\title{
COMUNICAÇÃo
}

\section{CIMEX LECTULARIUS, L. (LA CHINCHE COMUN DE CAMA) TRASMISOR DE TRYPANOSOMA CRUZI}

\author{
Miguel Eduardo Jörg
}

En 1982, el autor de esta comunicación publicó ${ }^{2}$ los resultados de una experimentación cuyos objetivos eran: 1. Verificar numéricamente la facilidad de infestación de Cimex lectularius, la chinche común de cama por el Trypanosoma cruzi. 2. Comprobar numéricamente con que frecuencia Cimex lectularius puede trasmitir la ingección tripanosómica por la picadura. 3. Averiguar cuanto tiempo persiste en el Cimex lectularius la infestación por el Trypanosoma cruzi, una vez que la misma se ha estabelecido. Los resultados fueron: I. Se logró la infestación de todos los ejemplares de $C$. lectularius $(\mathrm{n}=125)$ tras 8 exposiciones de 24 horas cada una, sobre un Akodon azarae azarae (ratón silvestre de campo) con infección natural por \&ypanosoma cruzi (presentaba un promedio de 100 tripomastigotes por gota gruesa de sangre). II. Se comprobó la infección experimental de 96,6\% de ratones blancos (cepa indeterminada pero sensible a la infección por el tripanosoma) $(\mathrm{n}=30)$ mediante la picadura por $C$. lectularius tras 15 dias de exposición. 22 ratones mostraron tripomastigotes en sangre entre 10 y 15 dias tras la exposición. 4 ratones mostraron infección leve $(2$ tripomastigotes por gota gruesa de sangre) 3 mostraron parásitos a los 30 dias, sólo evidenciables por exsanguinación y concentración. Un animal resultó negativo. III. La infestación de mantuvo en las chinches por lapsos variables pero prolongados hasta 320 dias. Se complementó la investigación parasitológica con observaciones sobre el ciclo vital y la resistencia al ayuno de $C$. lectularius, variable entre 30 y 92 dias.

La comunicación presente tiene por objetivo documentar en fotomicrografía la presencia evolutiva del Trypanosoma cruzi en un corte de ninfa estado I, a los 30 dias de haberse alimentado sobre un ratón con alta infección por $T$. cruzi. Por

\footnotetext{
Centro Médico de Mar del Plata, San Luis 1978, 7600 Mar del Plata, Argentina.

Recebido para publicacão em 25/06/92.
}

dificultades del corte microtómico se emplearon chinches recién nacidas. Se observa (Figura 1) gran acumulación parasitaria en el ventrículo gástrico y en el trayecto de salida del mismo. Si bien la mayoría de los parásitos muestran forma de esferomastigotes ${ }^{1}$, en detalle (a) con gran aumento pueden verificarse formas evolutivas flageladas; el recuadro (b) muestra la densidad de acumulación. No se ha comprobado la extensión del parasitismo al intestino terminal.

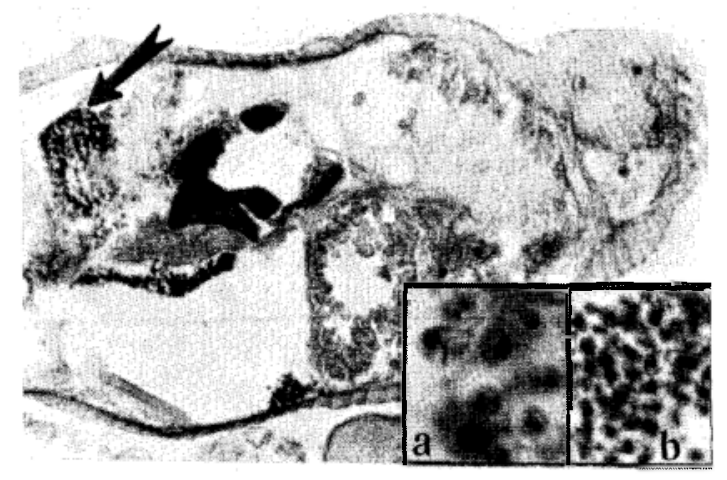

Figura 1 - Corte microtómico sesgado de ninfa I de Cimex lectularius, mostrando acumulación de formas evolutivas de Trypanosoma cruzi en ventrículo gástrico y su salida, a los 30 dias de haberse alimentado sobre un ratón con alta infección por tal parásito. a. con gram aumento y máxima resolución es visible una forma de evolución flagelar en el magma anterior. b. muestra la densidad parasitaria, predomínio de esferomastigotes. Tinción Giemsa.

Con respecto a la posible importancia epidemiológica de Cimex lectularius como trasmisor de la enfermedad de Chagas, la única verificación conocida por el autor es la comprobación (realizada colaborando al profesor Salvador Mazza) en el barrio Gorriti de la ciudad de San Salvador de Jujuy, Argentina, en 1938 donde sobre un $40 \%$ de Triatoma infestans infestados por Trypanosoma cruzi se encontró un $4 \%$ de chinches igualmente infestadas, aunque el número de ejemplares examinados fue muy bajo en relación el número de vinchucas.

Un caso de enfermedad de Chagas aguda, en pleno barrio residencial de la ciudad Buenos Aires (a 
Comunicação. Jörg ME. Cimex lectularius, L. (La chinche comun de Cama) Trasmisor de Trypanosoma cruzi. Revista da Sociedade Brasileira de Medicina Tropical 25:277-278, out-dez, 1992.

500 metros del Hospital Militar Central) fue visto por el médico Luis Lausi ${ }^{3}$ y ratificado por el autor, sólo atribuible a la trasmisión por chinches de cama, ya que el niño afectado compartía la cama - con abundantes hemípteros - con un pariente altamente sueropositivo para $T$. cruzi.

Se reitera por ello que la chinche común de cama puede actuar como trasmisor de la enfemedad de Chagas con posible importancia epidemiológica por: a. la facilidad con que se infesta por el T. cruzi; b. el elevado índice de infección que es capaz de producir en ratones por picadura reiterada, verosímilmente por regurgitación; c. la prolongada persistencia de parásitos vivos y móviles en el tubo digestivo de los imagines; d. la significativa resistencia al ayuno de la chinche.

\section{REFERÊNCIAS BIBLIOGRÁFICAS}

1. Brack A. Elekytonmikroskopische Untersuchungen ueber Lebenzyklus von Trypanosoma cruzi. Acta Tropica 25:289, 1968.

2. Jörg ME. Cimex lectularius L (La chinche común de cama) trasmisor de Trypanosoma cruzi. Prensa Medica Argentina 69:528, 1982.

3. Lausi L. Enfermedad de Chagas autóctona en Buenos Aires. Dia Médico 45:1156, 1973. 